\title{
Towards Developing an Aerial Mapping System for Stockpile Volume Estimation in Cement Plants
}

DOI:

10.2514/6.2021-0578

\section{Document Version}

Accepted author manuscript

Link to publication record in Manchester Research Explorer

\section{Citation for published version (APA):}

Alsayed, A., Nabawy, M. R. A., Yunusa-Kaltungo, A., Arvin, F., \& Quinn, M. K. (2021). Towards Developing an Aerial Mapping System for Stockpile Volume Estimation in Cement Plants. In AlAA Scitech 2021 Forum (pp. 1-8). (AIAA Scitech 2021 Forum). American Institute of Aeronautics and Astronautics . https://doi.org/10.2514/6.20210578

\section{Published in:}

AIAA Scitech 2021 Forum

\section{Citing this paper}

Please note that where the full-text provided on Manchester Research Explorer is the Author Accepted Manuscript or Proof version this may differ from the final Published version. If citing, it is advised that you check and use the publisher's definitive version.

\section{General rights}

Copyright and moral rights for the publications made accessible in the Research Explorer are retained by the authors and/or other copyright owners and it is a condition of accessing publications that users recognise and abide by the legal requirements associated with these rights.

\section{Takedown policy}

If you believe that this document breaches copyright please refer to the University of Manchester's Takedown Procedures [http://man.ac.uk/04Y6Bo] or contact uml.scholarlycommunications@manchester.ac.uk providing relevant details, so we can investigate your claim.

\section{OPEN ACCESS}




\title{
Towards Developing an Aerial Mapping System for Stockpile Volume Estimation in Cement Plants
}

\author{
Ahmad Alsayed ${ }^{1,2}$, Mostafa R. A. Nabawy ${ }^{3,4}$, Akilu Yunusa-Kaltungo ${ }^{5}$, \\ Farshad Arvin ${ }^{6}$ and Mark K. Quinn 7 \\ The University of Manchester, Manchester, MI 3BB, United Kingdom
}

\begin{abstract}
Integrated manufacturing systems such as cement processes are heavily dependent on stockpiles of different materials that serve as inputs to the different stages of production. Accurate estimation of material volume contained in these stockpiles is central to process profitability and waste elimination/minimisation. However, accurate estimation of stock within the cement industry is challenging owing to the unevenness of stock shapes and harsh environmental conditions (e.g. dust, temperature, humidity, etc.). This work provides a set of results obtained from preliminary investigation into the feasibility of deploying a low-cost aerial system to estimate stockpile volumes in open and semi-confined spaces within cement plants. An outdoor stockpile was first mapped using GPS for localisation, while 1D LiDAR and barometer were used for the stockpile height estimation. Visual inspection of the reconstructed stockpile surface showed strong correspondence to the actual stockpile. A second mission was conducted in a semi-confined space. The reconstructed surface appearance was inaccurate due to GPS-related issues; however, the volume was still estimated with reasonable accuracy, within $2.4 \%$ error. Future recommendations on upgrading the developed system to work within confined spaces are provided.
\end{abstract}

\section{Introduction}

Unmanned Arial Vehicles (UAVs) are widely deployed to tackle a variety of challenges within both military and civilian sectors. Typical applications involve reconnaissance, surveillance, mapping, among many others [1-4]. This work seeks to identify means of realising UAV inspection and monitoring missions within cement plants, a novel application in a very challenging environment. To name a few challenges, cement plants are known to be heavily dust-laden environments with high temperatures and humidity. This combination of harsh weather conditions (especially the fine dust) significantly impedes sensor signals. This is besides other operational challenges such as the limitations on GPS signal within these spaces which are bound to affect navigation strategies as well as the requirement to fly in many occasions beyond the pilot's line of sight. However, successful demonstration of such

\footnotetext{
${ }^{1}$ Ph.D. Candidate, Department of Mechanical, Aerospace and Civil Engineering, The University of Manchester, Manchester M1 3BB, UK.

${ }^{2}$ Department of Mechanical Engineering, Umm Al-Qura University, Al Abdeyah, Makkah 5555, Saudi Arabia.

${ }^{3}$ Department of Mechanical, Aerospace and Civil Engineering, The University of Manchester, Manchester M1 3BB, UK, and Senior Member AIAA.

${ }^{4}$ Aerospace Engineering Department, Faculty of Engineering, Cairo University, Giza 12613, Egypt, and Senior Member AIAA.

${ }^{5}$ Senior Lecturer, Department of Mechanical, Aerospace and Civil Engineering, The University of Manchester, Manchester M1 3BB, UK.

${ }^{6}$ Lecturer, Department of Electrical and Electronic Engineering, The University of Manchester, Manchester M1 3BB, UK.

${ }^{7}$ Senior Lecturer, Department of Mechanical, Aerospace and Civil Engineering, The University of Manchester, Manchester M1 3BB, UK.
} 
missions will have a significant impact. From a business perspective, increased use of robotic inspection assets can reduce plant downtime costs that often emerge from routine physical inspection/maintenance $[5,6]$. From a safety perspective, robots assisted missions within such highly hazardous industrial environments can drastically improve health and safety measures through eliminating/minimising human exposure levels, thereby improving the wellbeing of people as well as protecting the environment. Figure 1 shows the rate of fatal and non-fatal injuries to workers in Great Britain over the last six years based on the data provided in [7]. The lack of decline in reported incidents highlights the ongoing need to improve safety practices.
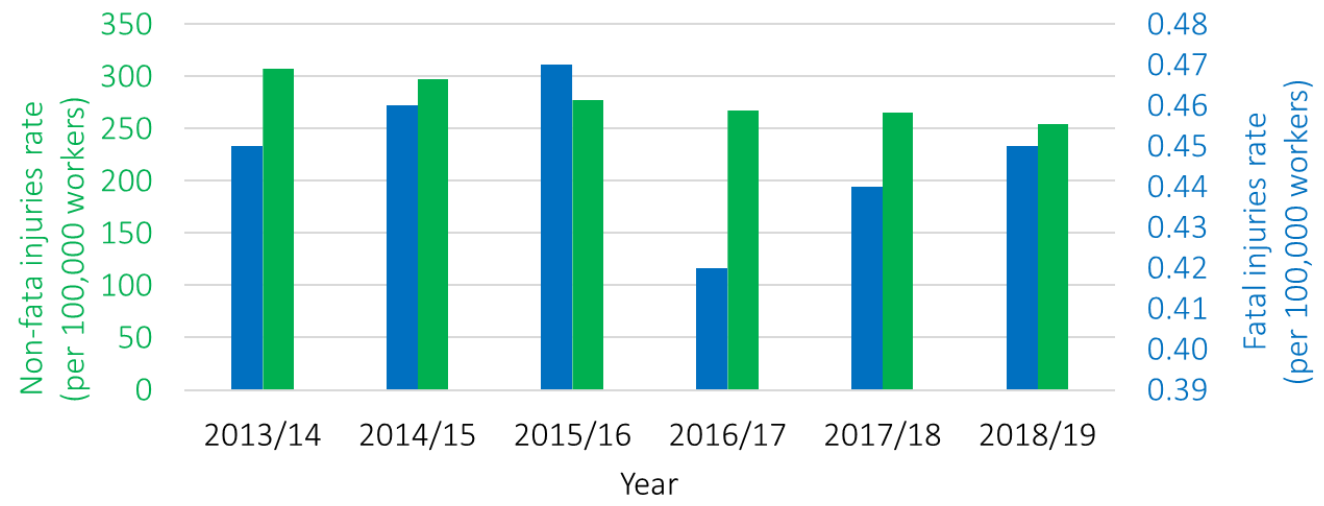

Figure 1: Reported injuries to workers in the UK in the last six years based on data collected in [7].

In this study, emphasis is placed on the application of drones for estimating raw material stockpile volumes within a prominent UK-based cement plant, owing to the criticality, frequency, and labour-intensiveness of such activities. The implications of wrong stock estimates could be far reaching. For instance, most businesses rely on stakeholders and lenders for generation of funds to implement capital (CAPEX) and operational expenditures (OPEX). At the end of pre-defined business cycles, stakeholders anticipate dividends while interests are paid to lenders. Based on this premise, manufacturing profitability is highly correlated with effective management of working capital of which inventory management plays a significant role. In theory, the higher the inventory turnover, the higher the possibility of reducing the working capital but this is only a reality when a manufacturer has an accurate knowledge of its stock or inventory. In addition to these primary effects, there are other indirect implications of poor stock level estimations in the cement processes such as higher energy consumption due to idling of transport systems (e.g. roots blowers, pneumatic transport pumps, belt conveyors, bucket elevators, compressors, etc.). Some of the most advanced cement stockpiles are furnished with level probes or dips for material estimation. As the extraction of material increases, the irregularity of the stockpiles also increases, thereby making some probes or dips sense the presence of materials that may not be extractable, thereby leading to continuous operation of downstream transport systems. Finally, the current regime of stock estimation requires that employees routinely visit stockpiles which are often in confined spaces, thereby raising risks of entrapment and dust inhalations.

In order to alleviate the aforementioned challenges, the current study leans itself towards the notion that UAVs possess the capability to provide quick, efficient, and accurate volume estimation. It is well-established that UAVs with a normal camera can produce 3D models, photogrammetric maps, and digital elevation models [8]; hence UAVs are already being used for missions involving stockpile volume estimation. Arango and Morales [9] compared the accuracies of material stockpile volume estimates obtained via electronic/optical survey instrument (i.e. total stations theodolite) to those acquired via UAV missions. Results indicated that the difference between the estimated and actual volumes was $2.88 \%$ and $0.67 \%$ for total stations theodolite and UAV-based mission, respectively [9]. Other related studies have also reported encouraging outcomes with regards to exploring the proficiency of drone-assisted surveying and stockpile measurement [10,11]. He et al. [10] estimated the size of stockpiles carried on barges using a traditional method (reshaping a stockpile to a trapezoidal shape and measure the volume with a measurement tool like a tape), laser scanning, and aerial photogrammetry. Results show similar accuracy levels for the three methods; however, in terms of time efficiency, aerial photogrammetry required an 
average of $20 \mathrm{~min}$ for data collection and processing, whereas the traditional method and laser scanning required $120 \mathrm{~min}$ and 40min for the same stockpile, respectively. Kaamin et al. [11] used aerial photogrammetry to estimate a landfill stockpile volume. While the study did not discuss the accuracy of the measured volume, it illustrated the change of the landfill over a two-month period. However, a common limitation of the aforementioned studies is that the provided demonstrations only considered daylight missions with strong GPS signals; hence, such solutions cannot be adopted when operating in the harsh environmental conditions of cement plants. In this study, some of the operational challenges within cement plants are considered as the selected scanning sensor can operate in dark, humid, and dusty environments. Nevertheless, we still used GPS signal for localisation which hinders deployment within fully confined spaces. That said, an adequate indoor localisation will be adopted in future work when missions in confined spaces are considered.

\section{Volume Estimation in a Cement Plant}

\section{A. Cement Plant}

The case study cement plant is Hope Works in Derbyshire (Breedon Cement PLC) which is the largest fully integrated cement process plant in the UK. The plant produces approximately 1.5 million tonnes of cement annually accounting for $15 \%$ of the UK's total cement production capacity. The plant is made up of five primary stages, namely quarrying, crushing, raw milling, kiln burning, and cement grinding. Limestone is the main component of cement and it is extracted through quarrying although it is quite common for such limestone beds to have other primary components (e.g. alumina and iron ore) embedded in them. The fourth primary component is river sand or silica [12]. The crushing stage reduces large lumps of quarried material into sizes acceptable by the raw milling stage, prior to being pyro-processed in the rotary kilns to produce clinker $[5,6]$. The clinker from the kilns is then ground with gypsum to produce cement. Each of the described process stages is associated with its input (also known as feed) and output inventory which is often stored in fully open, semi-confined (e.g. sheds), or fully confined spaces (e.g. silos and hoppers). In this study, data were obtained from missions for one fully open gypsum stockpile as well as one semi-confined clinker shed.

\section{B. Instrumentation}

The UAV used was a quadcopter with a frame measuring $585 \mathrm{~mm}$ as depicted in Figure 2. The quadcopter was controlled using a Pixhawk flight controller. It was fitted with a GPS sensor to provide location, and a barometer to measure altitude. A 1D Light Detection and Ranging (LiDAR) was also integrated to measure the distance between the quadcopter and the ground. The used LiDAR is a TF Mini LiDAR with a FOV of $2.3^{\circ}$. It can detect distances up to 12 meters in normal indoor conditions and 7 meters in normal outdoor conditions. The LiDAR was connected to a Raspberry Pi 3 micro-board to run the scanning and save the data to a memory card. In the ground station, there are two computers; one to monitor the flight data and another to run and monitor the scanning system. A long-range WiFi router was used to create connection between the UAV and the ground station.

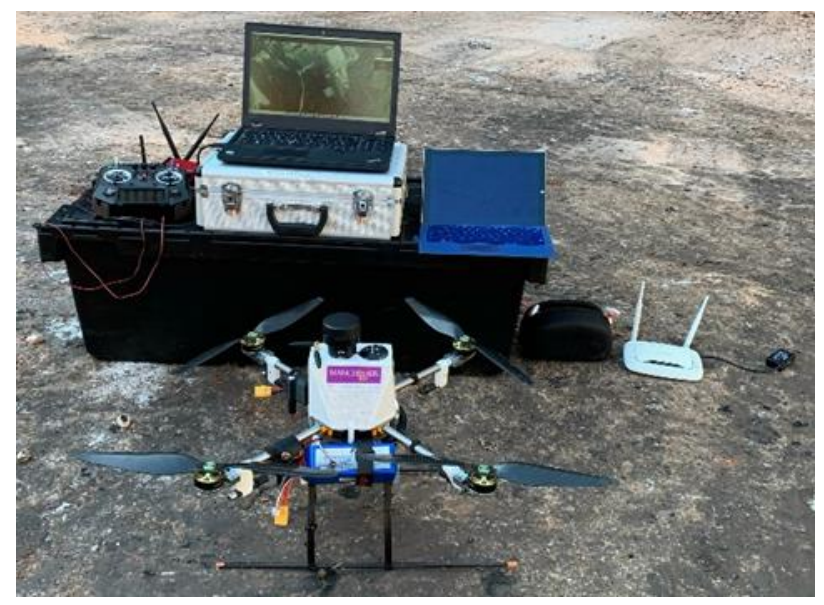

Figure 2: Aerial mapping system for stockpile volume estimation in cement plants including quadrotor with integrated sensors and ground station. 


\section{Data Filtering and Processing}

Three sets of data were collected from the flight tests. The first set included the GPS time, coordinate, and timestamp data, which had an average sampling rate of $5 \mathrm{~Hz}$. The second set included the UAV local timestamp and barometer data, which had an average sampling rate of $9.85 \mathrm{~Hz}$. The final set included the Raspberry Pi local time, timestamp, and depth readings form the LiDAR, which had an average sampling rate of $8.6 \mathrm{~Hz}$. GPS provided quadcopter location, barometer provided altitude information with respect to the take-off level, and LiDAR provided the vertical distance between the quadcopter and the ground.

The GPS time has a micro POSIX ${ }^{\circledR}$ format, where the POSIX ${ }^{\circledR}$ time represents number of seconds (including fractional seconds) elapsed since 00:00:00 1-Jan-1970 UTC [13]. The MATLAB function datetime was used to convert POSIX ${ }^{\circledR}$ time format to local time. An alternative Matlab function was used to convert the GPS latitudes and longitudes to a two-dimensional projection, $x$ and $y$ axes [14].

In order to match the three sets of data (GPS, barometer, and LiDAR), a shared start and end time was defined. Since the three data sets varied in sampling rates, the resample function within MATLAB was used to transfer the data onto a regular grid based on a unified sample rate of $10 \mathrm{~Hz}$. Figure 3 shows an example for the resampled data superimposed on the original data.

To estimate the stockpile volume, the difference between readings from barometer and LiDAR was used to evaluate the height of the pile, while the GPS data was used to define $x$ and $y$ positions. In order to construct the 3D surface as well as measure the volume of the pile, 2-D grid coordinates (based on $x$ and $y$ data) were obtained using the meshgrid function within MATLAB. The griddata function was then used to interpolate the surface at the query points specified by the meshed 2-D grid and return the interpolated values that represent the pile height.

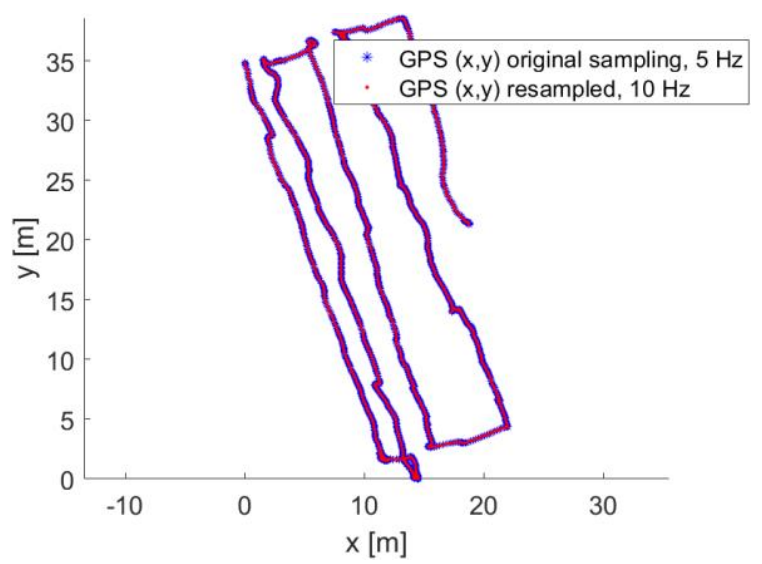

(a)

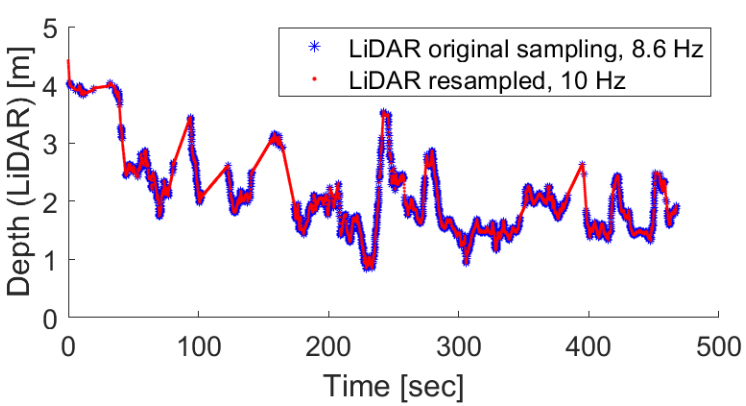

(b)

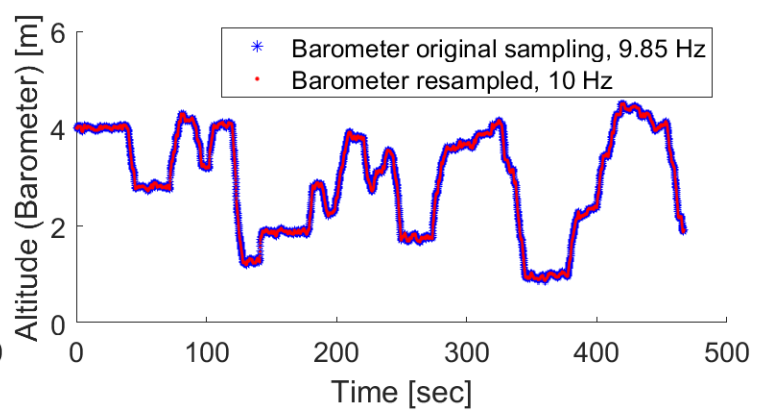

(c)

Figure 3: (a) Quadcopter position from GPS coordinates before and after resampling. (b) LiDAR original and resampled readings. (c) Barometer original and resampled readings. Data are for the outdoor mission. 


\section{Preliminary Results}

Figure 4-a shows an outdoor stockpile from the case study cement plant. A mission was conducted with the quadcopter and data were gathered as demonstrated in Figure 3. Collected data were processed, and Figure 4-b shows the generated surface of the stockpile. The volume estimate of this pile is $1021.5 \mathrm{~m}^{3}$. The red scatters in the figure illustrate the measured stockpile heights from the UAV, whereas the exterior is an interpolated surface. While information on the actual volume of the outdoor stockpile is not available to compare against our estimated volume, there is strong correspondence between the actual and reconstructed piles based on visual inspection.

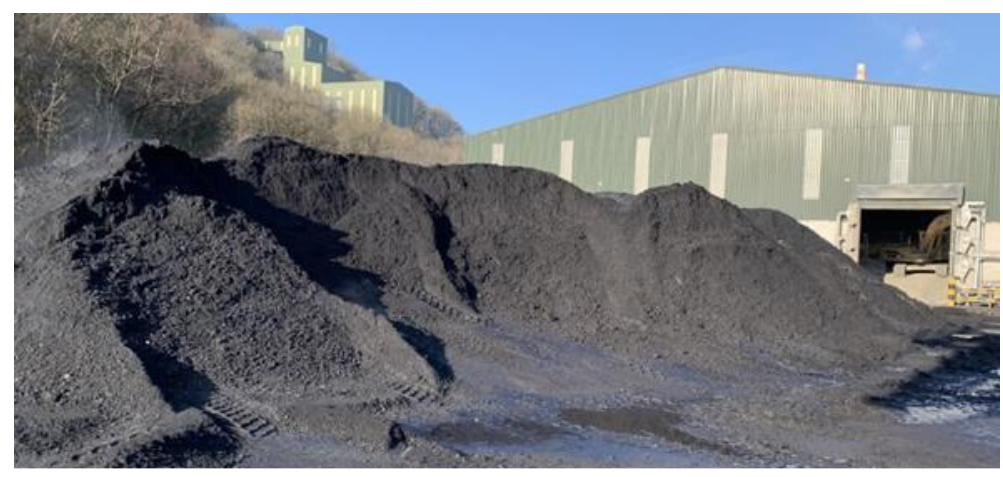

(a)

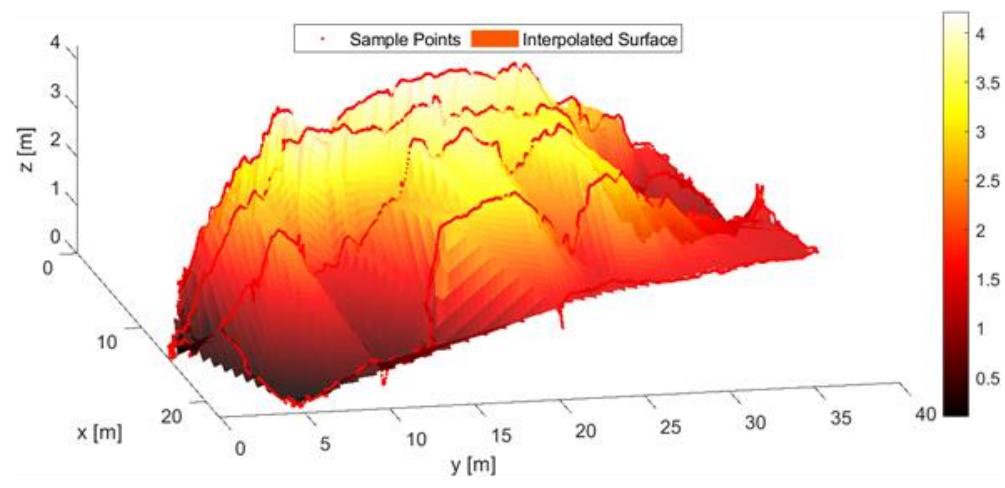

(b)

Figure 4: (a) Real outdoor stockpile, and (b) reconstructed surface of the stockpile.

The result for the outdoor stockpile was measured with the UAV position being localised with an average of fourteen satellites. Another test was conducted within a semi-confined space (Figure 5-a), where the average number of the satellites reduced to eight. The semi-confined space was a shed with one of its sides open. This reduction of satellites led to a corresponding reduction in the accuracy of quadcopter localisation. Moreover, the metal sheets from which the shed is made may have had an effect on the efficiency of the GPS positioning resolution [15]. The reconstructed stockpile depicted in Figure 5-b highlights imprecisions of relying on GPS for localisation within the semi-confined space; on the other hand, Figure 5-c shows a reconstructed pile of the same stockpile while using the planned trajectory (not the actual GPS data). To further demonstrate this imprecision, the top view of the planned flight trajectory (the zig-zag trajectory used for the reconstruction shown in Figure 5-c) is shown in Figure 6-a which was not well generated from the recorded flight trajectory based on the GPS coordinates (trajectory used for the reconstruction shown in Figure 5-b) as could be seen in Figure 6-b. That said, the estimated volume of the pile was $24.4 \mathrm{~m}^{3}$ which leads to a remarkably reasonable absolute error of $2.4 \%$. Note that in estimating the error, the actual pile volume is based on the fact that the pile was dumped on the testing day from a 30-ton capacity dump truck which has a maximum load-carrying capacity of $25 \mathrm{~m}^{3}$. 


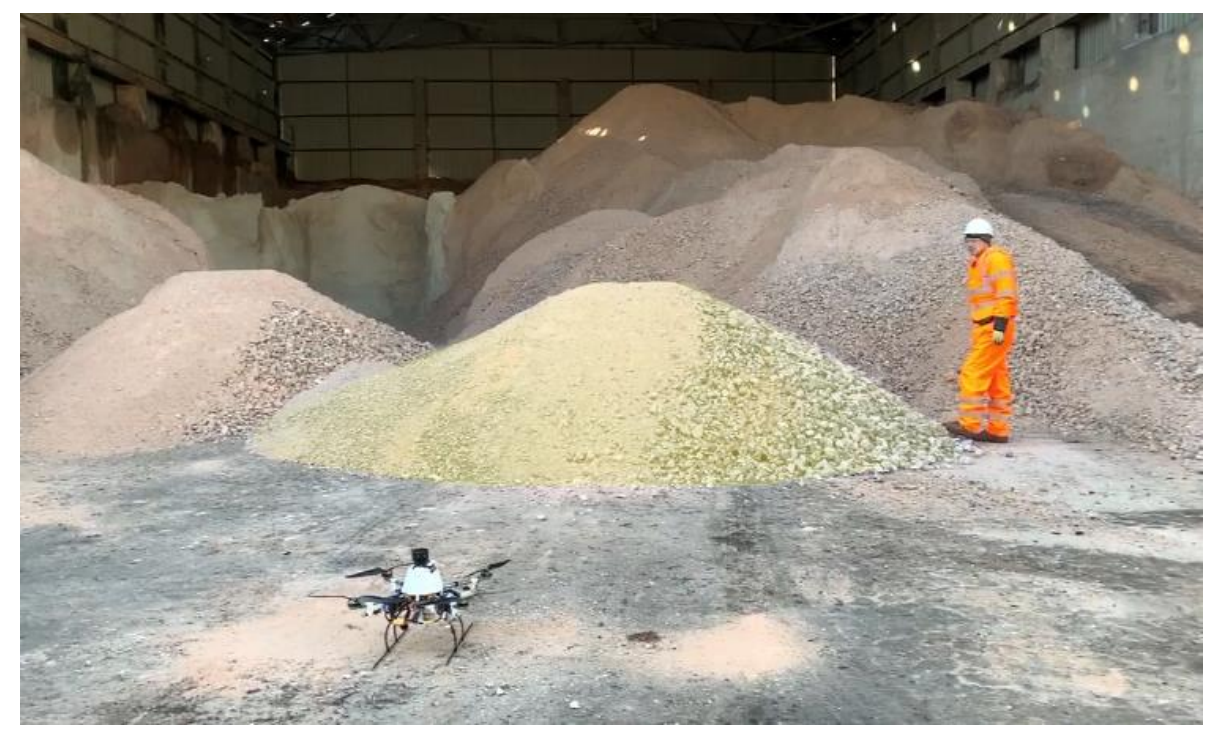

(a)

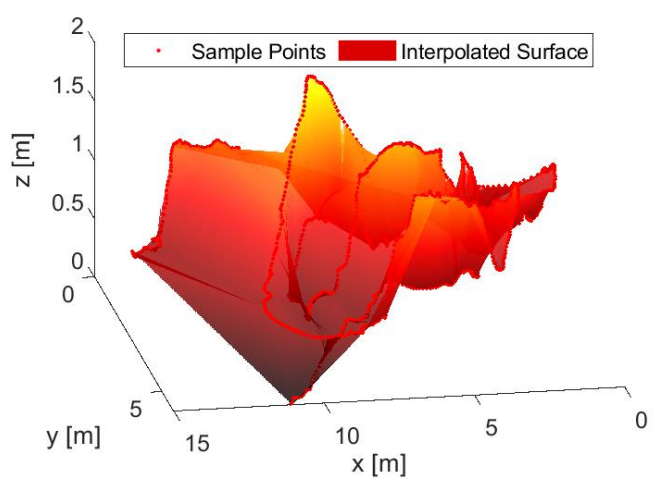

(b)

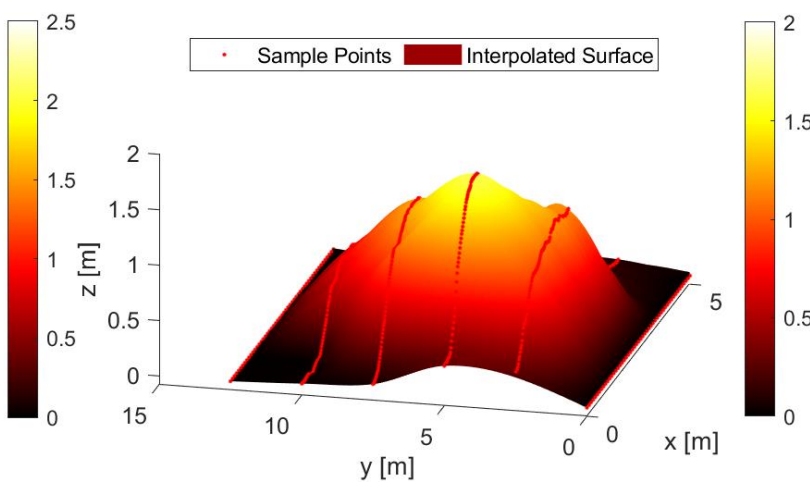

(c)

Figure 5: (a) A small pile of gypsum located in a semi-confined space. (b) Reconstructed surface of the pile using GPS position readings (Collected GPS trajectory data is shown in Figure 6-b) showing imprecisions due to reduced GPS positioning resolution; however, the volume was still estimated with good accuracy, within $\mathbf{2 . 4 \%}$. (c) Reconstructed surface of the small pile using the estimated pile height and planned trajectory data (planned trajectory data is sketched in Figure 6-a). 


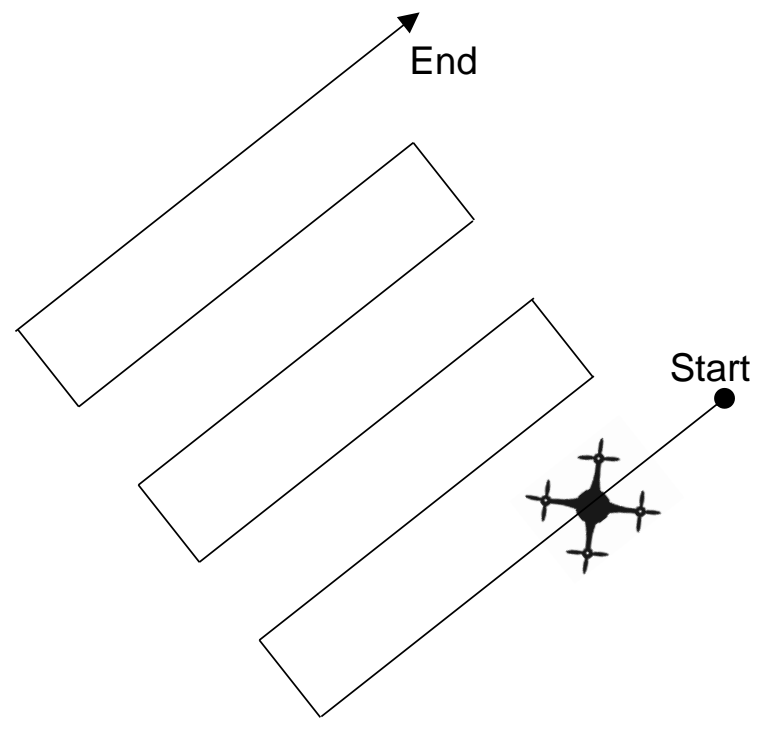

(a)

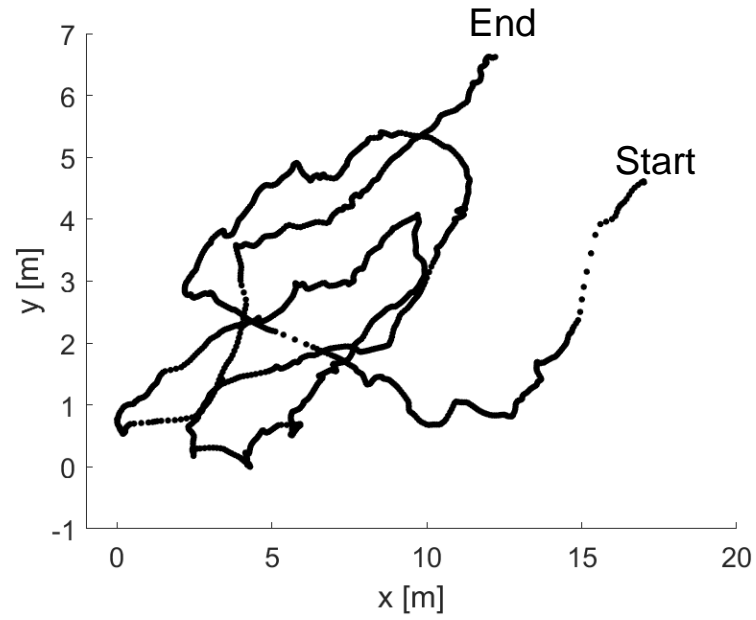

(b)

Figure 6: (a) Top view sketch of the planned flight trajectory (a zig-zag trajectory). (b) The recorded flight trajectory from the GPS coordinates.

\section{Concluding Remarks and Further Research}

An outdoor stockpile was mapped using GPS for localisation together with LiDAR and barometer for depth measurement. The 3D surface of the reconstructed stockpile showed significant correspondence to the actual stockpile. Another test was conducted in a semi-confined space; however, the reconstructed 3D surface was inaccurate due to low number of GPS satellites which in turn led to imprecise localisation. However, the volume was still estimated with good accuracy ( $2.4 \%$ absolute error). Further work will re-consider missions within semi and fully confined spaces using both simulation and experimental tools where the quad-rotor will be upgraded with obstacle detection and collision avoidance sensors. Moreover, to increase mapping accuracy while ensuring a lowcost solution, methods to enhance mapping capabilities of 1D LiDAR sensors will be considered. Finally, the effect of dust on the performance of these sensors, which is expected to be exaggerated in confined spaces, will be fully assessed. It is anticipated that a successful full demonstration of such aerial system will eliminate or at least minimise the need for sending workers to high-risk areas within cement plants.

\section{Acknowledgments}

The authors are immensely appreciative of the support offered by Breedon Cement (Hope Works, Hope Valley), especially the Reliability Engineering and Maintenance Departments for the access granted to the entire process lines during data collection. The authors would also like to acknowledge the technical support rendered by Professor William Crowther, Mr Kristopher Kabbabe, and Mr Ethan Bond during mission planning and field-based deployment.

\section{References}

[1] Nex, F., and Remondino, F. "UAV for 3D Mapping Applications: A Review." Applied Geomatics, Vol. 6, No. 1, 2014, pp. 1-15. https://doi.org/10.1007/s12518-013-0120-x.

[2] Ahmed, M. R., Abdelrahman, M. M., ElBayoumi, G. M., and ElNomrossy, M. M. "Optimal Wing Twist Distribution for Roll Control of MAVs.” The Aeronautical Journal, Vol. 115, No. 1172, 2011, pp. 641-649. https://doi.org/10.1017/S0001924000006333.

[3] Nabawy, M. R. A., ElNomrossy, M. M., Abdelrahman, M. M., and ElBayoumi, G. M. "Aerodynamic Shape Optimisation, Wind Tunnel Measurements and CFD Analysis of a MAV Wing.” The Aeronautical Journal, Vol. 116, 
No. 1181, 2012, pp. 685-708. https://doi.org/10.1017/S000192400000717X.

[4] Floreano, D., and Wood, R. J. "Science, Technology and the Future of Small Autonomous Drones." Nature, Vol. 521, No. 7553, 2015, pp. 460-466. https://doi.org/10.1038/nature14542.

[5] Yunusa-Kaltungo, A., Kermani, M. M., and Labib, A. "Investigation of Critical Failures Using Root Cause Analysis Methods: Case Study of ASH Cement PLC." Engineering Failure Analysis, Vol. 73, 2017, pp. 25-45. https://doi.org/10.1016/j.engfailanal.2016.11.016.

[6] Yunusa-Kaltungo, A., and Labib, A. "A Hybrid of Industrial Maintenance Decision Making Grids." Production Planning \& Control, 2020, pp. 1-18. https://doi.org/10.1080/09537287.2020.1741046.

[7] Health and Safety Statistics. The Journal of the Royal Society for the Promotion of Health. 5. Volume 99, 222. https://www.hse.gov.uk/statistics/. Accessed Dec. 12, 2019.

[8] Rhodes, R. K. UAS as an Inventory Tool: A Photogrammetric Approach to Volume Estimation. University of Arkansas, 2017.

[9] Arango, C., and Morales, C. A. "COMPARISON BETWEEN MULTICOPTER UAV AND TOTAL STATION FOR ESTIMATING STOCKPILE VOLUMES.” ISPRS - International Archives of the Photogrammetry, Remote Sensing and Spatial Information Sciences, Vols. XL-1/W4, No. 1W4, 2015, pp. 131-135. https://doi.org/10.5194/isprsarchives-XL1-W4-131-2015.

[10] He, H., Chen, T., Zeng, H., and Huang, S. "Ground Control Point-Free Unmanned Aerial Vehicle-Based Photogrammetry for Volume Estimation of Stockpiles Carried on Barges.” Sensors, Vol. 19, No. 16, 2019 , p. 3534. https://doi.org/10.3390/s19163534.

[11] Kaamin, M., Asrul, N., Daud, M. E., Suwandi, A. K., Sahat, S., Mokhtar, M., and Ngadiman, N. "Volumetric Change Calculation for a Landfill Stockpile Using UAV Photogrammetry." International Journal of Integrated Engineering, Vol. 11, No. 9 Special Issue, 2019, pp. 53-62.

[12] Iheukwumere-Esotu, L. O., and Yunusa Kaltungo, A. "Assessment of Barriers to Knowledge and Experience Transfer in Major Maintenance Activities.” Energies, Vol. 13, No. 7, 2020, p. 1721. https://doi.org/10.3390/en13071721.

[13] Convert MATLAB Datetime to POSIX Time - MATLAB Posixtime - MathWorks United Kingdom. https://uk.mathworks.com/help/matlab/ref/datetime.posixtime.html. Accessed Nov. 30, 2020.

[14] Spherical To Azimuthal Equidistant - File Exchange - MATLAB Central. https://uk.mathworks.com/matlabcentral/fileexchange/28848-spherical-to-azimuthal-equidistant. Accessed Nov. 30, 2020.

[15] Mohamed, A. S., Doma, M. I., and Rabah, M. M. "Study the Effect of Surrounding Surface Material Types on the Multipath of GPS Signal and Its Impact on the Accuracy of Positioning Determination." American Journal of Geographic Information System, Vol. 8, No. 5, 2019, pp. 199-205. https://doi.org/10.5923/j.ajgis.20190805.01. 